Cregan, J., Dunlop, E. E. \& Hayward, N. J. (1953). Brit. med. F. ii, r248.

Cregan, J. \& Hayward, N. J. (1953). Brit. med. F. i, 1356.

Cushing, H. \& Livingood, L. E. (1900). Fohns Hopk. Hosp. Rep. 9, 543.

Ellinger, P. \& Hardwick, S. W. (1947). Brit. med. F. i, 672.

Friedman, T. E., Kmieciak, T. C., Keegan, P. K. \& Sheft, B. B. (1948). Gastroenterology, II, 101.

Girdwood, R. H. (1953). Lancet, 265, 53 .

Girdwood, R. H. (1954). Brit. med. F. ii, 954.

Glass, G. B. J. (1954). Int. Congr. Haemat. v. Paris. (In the Press.)

Harris, L. J. \& Abbasy, M. A. (1937). Lancet, 233, I429.

Hewetson, J. T. (1904). Brit. med.F. ii, 1457.

Klatskin, G. \& Krehl, W. A. (1950). F. clin. Invest. 29, 1528.

Lascelles, J. \& Woods, D. D. (1952). Brit. F. exp. Path. 33, 288.

Mollin, D. L. \& Ross, G. I. M. (1953). Brit. med. F. ii, 640.

Najjar, V. A. (1944). Fohns Hopk. Hosp. Bull. 74, 392.

Najjar, V. A. \& Holt, L. E. Jr. (1941). Fohns Hopk. Hosp. Bull. 69, 476.

Oppel, T. W. (1948). Amer. F. med. Sci. 215, 76.

Quick, A. J. (1940). Amer. F. clin. Path. 10, 222.

Schilling, R. F. (1953). F. Lab. clin. Med. 42, 860.

Strauss, E., Lowell, F. C. \& Finland, M. (194I). F. clin. Invest. 20, 189.

Unglaub, W. C., Rosenthal, H. L. \& Goldsmith, G. R. (1954). F. Lab. clin. Med. 43, I43.

Welch, A. D., Scharf, V., Heinle, R. W. \& Meacham, G. C. (1952). Fed. Proc. 11, 308.

Williams, R. D., Mason, H. L., Power, M. H. \& Wilder, R. M. (1943). Arch. intern. Med. 71, 38.

Wright, I. S. (1938). Ann. intern. Med. 12, 5 I6.

Yiengst, M. J. \& Shock, N. W. (r949). Fed. Proc. 8, 173.

\title{
Mineral Metabolism in Alimentary Disease
}

\section{By D. A. K. Black, Department of Medicine, The Royal Infirmary, Manchester}

Diseases of the alimentary tract affect mineral metabolism in two main ways-by deprivation or malabsorption of dietary minerals, and by loss in vomitus or faeces of the minerals contained in alimentary-tract secretions. The interference with absorption which must underlie both these mechanisms may be mechanical, as in pyloric stenosis; or may be functional, as in idiopathic steatorrhoea. The two mechanisms may indeed both be operative, as in intestinal obstruction, where food intake is valueless and at the same time large amounts of minerals are lost by vomiting and by continuous aspiration of alimentary secretions. In general, chronic alimentary disease causes mineral malnutrition mainly by deprivation and malabsorption of food minerals, whereas in acute catastrophes the effects of loss of alimentary secretions predominate. Since the mineral composition of alimentary secretions is much more akin to that of extracellular fluid than to that of cellular and skeletal tissue, the acute catastrophes cause the syndrome of dehydration, whereas chronic illness leads to a bewildering variety of mineral disturbances involving intracellular ions such as potassium and phosphate, and bone minerals such as calcium and phosphorus. Again, the distinction is not absolute, for potassium depletion is demonstrable both in acute and chronic alimentary-tract disease. Besides straightforward deprivation, malabsorption, or loss of minerals, alimentary-tract disease can influence mineral metabolism indirectly by way of general nutritional disturbance, as in the sequence : anorexia $\rightarrow$ deficient intake of calories and proteins $\rightarrow$ hypoproteinaemia $\rightarrow$ low plasma volume $\rightarrow$ renal retention of salt and water $\rightarrow$ oedema. 
Similar sequences involving hepatic cirrhosis or conditioned thiamine deficiency no doubt exist, but in this presentation we shall have enough to do in summarizing the 'simple' direct effects. The only workable way of doing this in short compass is to consider different minerals seriatim in terms of the mechanisms and effects of their respective depletions in alimentary disease. Important interrelations between the various depletions certainly exist, and may even obtrude themselves clinically; for example, primary potassium depletion can lead to disturbance both of acidbase balance and of extracellular-fluid volume (Cooke, Segar, Reed, Etzwiler, Vita, Brusilow \& Darrow, 1954). Different depletions often exist independently, and in varying quantity in different patients. Here we can only describe separate pieces, and not the varying clinical patterns which they combine to form. As examples of mainly intracellular ions, we shall consider potassium and iron; calcium as a skeletal ion, and sodium as a mainly extracellular ion.

Potassium. Among the causes of potassium depletion, disease of the alimentary tract is quantitatively and qualitatively preponderant. Clinical potassium depletion was first recognized by Darrow (1946) in association with infantile gastro-enteritis, and subsequent surveys have uniformly shown that about nine out of ten instances of significant potassium depletion can be traced to alimentary disease, which also causes some of the largest depletions recorded. Potassium depletion has been demonstrated in pyloric stenosis, in gastro-enteritis, in ulcerative colitis and steatorrhoea, and even as a result of the long-continued abuse of laxatives. As might perhaps be expected from the diversity of possible causes, a number of mechanisms can operate to produce significant potassium depletion. These include deprivation of the dietary intake of potassium, which is usually of the order of $100 \mathrm{~m}$-equiv. $(4 \mathrm{~g})$ daily; increased loss of potassium in the stools; and loss of potassium by vomiting. The potassium content of alimentary secretions is only about a tenth of the sodium content, so that in acute disturbances sodium depletion predominates; but in chronic disease, the comparatively low content of potassium in secretions may yet lead to significant losses, partly because colonic absorption of potassium is much less complete than that of sodium, and partly because renal loss of potassium is greater than that of sodium with comparable body deficits of the two ions (Black, I953 $a, b$ ). When the disease necessitates operation, further losses of potassium occur as part of the katabolic response to surgery (Moore \& Ball, 1952). Potassium depletion may be suspected from a knowledge of the mechanisms likely to cause it, and its presence confirmed by the finding of a low serum potassium or the observation that added potassium is being retained in the body. Severe potassium depletion can cause muscle weakness, respiratory distress, renal and cardiac damage, and-more directly germane to the alimentary tract-anorexia and even paralytic ileus. It is therefore worth treating with potassium by mouth, and when this is precluded by vomiting, by cautious parenteral administration. A high concentration of potassium in the plasma perfusing the heart can lead to cardiac arrest, so the rate of administration must be limited, and the concentration of potassium in solutions for intravenous use no greater than $40 \mathrm{~m}$-equiv./1.; these precautions are specially important when there is oliguria, as may happen with concurrent sodium depletion. 
Iron. Even with an adequate oral intake of iron, faulty absorption of this mineral can still lead to significant depletion. It is generally agreed that faecal excretion of iron represents unabsorbed iron, and not iron secreted through the bowel wall. The absorption of iron has been reviewed by Granick (1949); the presence of free hydrochloric acid in the stomach increases the availability of dietary iron for absorption, and the iron is then transported through the intestinal mucosa in conjunction with apoferritin, the amount absorbed being greater when body stores of iron are low. Achlorhydria has long been recognized as a predisposing cause of iron-deficiency anaemia, usually precipitated by the physiological blood loss of the female reproductive life. More recently, impaired iron absorption has been demonstrated in the steatorrhoea syndrome, even in patients with neither achlorhydria nor overt diarrhoea. Alimentary disease, notably peptic ulcer and cancer of the stomach or colon, also causes iron depletion through haemorrhage. The consequences of iron loss by any of these mechanisms are similar-a microcytic anaemia, with lowered absolute indices (mean corpuscular volume, mean corpuscular haemoglobin and mean corpuscular haemoglobin concentration), sometimes associated with glossitis, dysphagia, and koilonychia not found in other types of anaemia of equal severity. Moderate failure of iron absorption can often be countered by giving ample amounts of ferrous iron salts by mouth; when this fails to correct the anaemia, or the patient is intolerant to iron, intravenous iron treatment is required.

Although recognized alimentary-tract disease either causes iron depletion or leaves iron absorption unaffected, we may note in passing that excessive iron deposits in the body, in the absence of blood transfusion, must be based on a long-continued increased absorption of iron, excessive in relation to bodily needs. Haemochromatosis can thus be regarded as an alimentary disease, in the sense of a failure of the normal regulation of iron absorption.

Calcium. The deficit of calcium needed to produce clinical symptoms or radiological evidence of osteomalacia is rather massive; the time required for its development is no doubt considerable, and it has only been reported in chronic diseases, notably idiopathic steatorrhoea. The pathogenesis of osteomalacia in association with steatorrhoea is somewhat complicated, as recent studies by Badenoch \& Fourman (1954) show. First of all, the presence of excessive fatty acid in the bowel leads to the formation of calcium soaps, whose calcium is not available for absorption; this can be corrected by giving a low-fat diet, with demonstrable improvement in calcium absorption. Then, it can be shown that vitamin $\mathrm{D}$ is poorly absorbed, for a further improvement in calcium absorption can be induced by vitamin $D$ given parenterally, or by very large doses of vitamin $\mathrm{D}$ given by mouth. Even so, the amount of calcium absorbed is still less than normal, indicating subnormal transport of calcium across the bowel wall even when adequate vitamin $D$ is available. Treatment of the osteomalacia consists in giving additional calcium as well as large doses of vitamin $\mathrm{D}$ by mouth.

Apart from osteomalacia, alimentary disease with vomiting can lead to tetany. It is doubtful how far the tetany of vomiting is due to depression by alkalosis of the ionization of plasma calcium, and how far it is due to depression of hydrogen ion 
concentration per se. It can usually be relieved by injection of calcium salts, but this fact does not firmly establish that the original mechanism involves calcium.

The prolonged treatment of peptic ulceration with large amounts of milk and alkalies can lead to calcium intoxication, with a raised plasma calcium, anorexia, vomiting, and renal failure associated with calcification of the renal tubules. Large amounts of alkalies are well tolerated for a limited period, but the combination of a high calcium diet and alkalies for long periods is dangerous.

Sodium. Vomiting and diarrhoea, however caused, are potent in producing sodium depletion; this is understandable in view of the large amount of fluid and salt secreted by the alimentary tract each day, and normally almost completely reabsorbed. The daily quantity of sodium is of the order of $600 \mathrm{~m}$-equiv. (equivalent to about $38 \mathrm{~g}$ salt) and of water about 81 . - amounts representing about twice the plasma volume, half the total extracellular fluid volume, and four times a normal daily intake. Continuous aspiration of alimentary secretion in patients with postoperative ileus or intestinal obstruction can quickly lead to serious dehydration. Interference with salt intake plays a subsidiary part, for the defences of the body against dietary deprivation of sodium are remarkably efficient, with renal excretion of salt falling to negligible amounts in a few days. Although the depletion of sodium itself is the paramount cause of the depletion of extracellular fluid which constitutes clinical dehydration, the anion composition of the fluid lost is also of importance. With loss of gastric secretion, chloride tends to be lost in excess of sodium, and an alkalosis may then complicate the sodium depletion; there is evidence that the kidneys can compensate by conserving chloride, but that their ability to do this is impaired by concurrent potassium depletion. A further complication is the administration of sodium salts, often by the patient himself, to control dyspepsia; it may prevent sodium depletion, but enhance potassium depletion, and allow an alkalosis to develop without dehydration. With diarrhoea or continuous aspiration of intestinal and pancreatic secretion, sodium is lost in excess of chloride, and acidosis is probable. The practical consequence is that replacement fluids for alimentary losses should be modified to supply different proportions of sodium and chloride, depending on the type of fluid lost. This can be done by incorporating varying amounts of lactate in the fluid given (Cooke \& Crowley, 1952); potassium replacement may also be needed before complete repair of the electrolyte disturbance can be achieved.

\section{SUMMARY}

Both in acute and chronic alimentary disease, disturbances of mineral metabolism are multiple and often interrelated. Acute disturbances tend to impinge mainly on extracellular fluid, whereas chronic disturbances involve cellular and skeletal minerals as well; potassium metabolism is affected by both types of disturbance. Treatment of mineral depletions should be based as far as possible on quantitative assessments, and some priority should be given to treating extracellular-fluid depletion, as other deficits can only be safely corrected when circulation and renal function are adequate. 
REFERENCES

Badenoch, J. \& Fourman, P. (1954). Quart. F. Med. 23, I65.

Black, D. A. K. (1953a). Lancet, 264, 305.

Black, D. A. K. ( $1953 b)$. Lancet, 264, 353 .

Cooke, R. E. \& Crowley, L. G. (1952). New Engl. F. Med. 246, 637.

Cooke, R. E., Segar, W. E., Reed, C., Etzwiler, D. D., Vita, M., Brusilow, S. \& Darrow, D. C. (1954). Amer. F. Med. 17, I80.

Darrow, D. C. (1946). F. Pediat. 28, 515.

Granick, S. (1949). Bull. N.Y. Acad. Med. 25, 403.

Moore, F. D. \& Ball, M. R. (1952). The Metabolic Response to Surgery, ist. ed. Springfield: C. C. Thomas.

\section{Food Allergy}

\section{By John A. Milne, Department of Pathology, Western Infirmary, Glasgow}

Much confusion has been caused by the unqualified use of the word allergy. As originally defined by von Pirquet (1906) allergy is 'any acquired specific alteration in the capacity to react which occurs in living organisms or tissues upon exposure to certain living or inanimate agents or substances'. This definition includes not only hypersensitive reactions, but also reactions involving decreased sensitivity such as immunity. For the purpose of this discussion the term allergy will be used to indicate only the hypersensitive type of reaction.

Immunological basis. In order to discuss food allergy it is necessary to consider first certain basic facts concerning allergic reactions, and the immunological basis of allergy. When an antigen first enters the body it stimulates the formation of specific antibodies. Some of these antibodies tend to persist in their free state in the circulating blood (circulating antibodies) and this would appear to constitute immunity. Others become incorporated into the substance of cells and become 'sessile' antibodies or fixed antibodies and so the allergic state is established. For example, a person given an injection of killed typhoid bacilli develops circulating antibodies in his blood stream which give him a relative immunity to typhoid fever. Further injection of typhoid bacilli tends to enhance the degree of immunity. Another person may ingest a foreign protein (e.g. egg white) inducing antibodies which eventually become sessile on the smooth muscle of his bronchial tree. Further exposure to egg white results in an attack of asthma. Why some people develop sessile antibodies and thus become hypersensitive is completely unknown.

In the example quoted above, the smooth muscle of the bronchus was mentioned as the site of fixation of the antibody. Various other sites may be affected, e.g. the nasal mucosa and conjunctiva, or the skin; tissues so affected are known as 'shock organs'. What actually takes place when a tissue containing sessile antibodies comes in contact with its specific antigen is not known. There is considerable experimental and clinical evidence to suggest that histamine or a closely related substance is released and that this release gives rise to the clinical picture. It is important to 